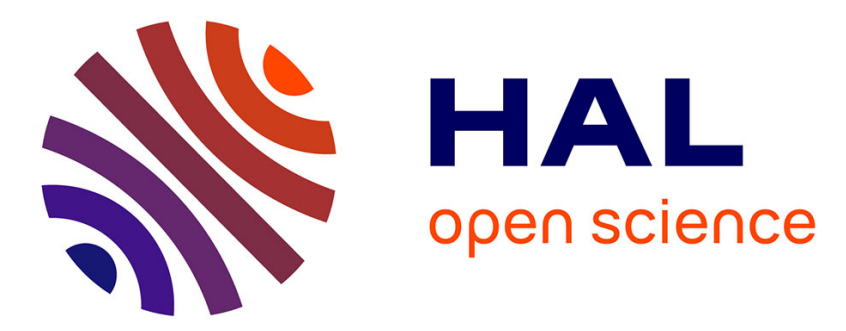

\title{
Drug approval decision times, international reference pricing and strategic launches of new drugs
}

\author{
Nicolas Houy, Izabela Jelovac
}

\section{To cite this version:}

Nicolas Houy, Izabela Jelovac. Drug approval decision times, international reference pricing and strategic launches of new drugs. 2014. halshs-01072741

\section{HAL Id: halshs-01072741 \\ https://shs.hal.science/halshs-01072741}

Preprint submitted on 8 Oct 2014

HAL is a multi-disciplinary open access archive for the deposit and dissemination of scientific research documents, whether they are published or not. The documents may come from teaching and research institutions in France or abroad, or from public or private research centers.
L'archive ouverte pluridisciplinaire HAL, est destinée au dépôt et à la diffusion de documents scientifiques de niveau recherche, publiés ou non, émanant des établissements d'enseignement et de recherche français ou étrangers, des laboratoires publics ou privés. 
Drug approval decision times, international reference pricing and strategic launches of new drugs

Nicolas Houy, Izabela Jelovac

October 2014 


\section{GATE Groupe d'Analyse et de Théorie Économique Lyon-St Étienne}

93, chemin des Mouilles 69130 Ecully - France

Tel. +33 (0)4 72866060

Fax $+33(0) 472866090$

6, rue Basse des Rives 42023 Saint-Etienne cedex 02 - France

Tel. +33(0)4 77421960

Fax. +33 (0)4 77421950

Messagerie électronique / Email : gate@gate.cnrs.fr

Téléchargement / Download : http://www.gate.cnrs.fr - Publications / Working Papers 


\title{
Drug approval decision times, international reference pricing and strategic launches of new drugs
}

\author{
Nicolas HouY* Izabela JELOVAC ${ }^{\dagger}$
}

October 7, 2014

\begin{abstract}
This paper analyzes how drug approval procedures influence the incentives of pharmaceutical firms to launch new drugs in the presence of international reference pricing. First, we show that the set of countries in which a firm commercializes a new drug is larger when countries do not approve this new drug simultaneously. We also show that a firm's best response to international reference pricing is to never launch a new drug sequentially as long as the difference in drug approval times between countries is small enough. Furthermore, we show that a firm's incentives to launch a new drug in one or another country are the same if the drug approval times are identical across countries or if the difference between approval times are small enough. However, we show that these incentives can change if the approval times differences across countries are large enough.

Key-Words: Drug launch timing, sequential launching, marketing authorization, international reference pricing.

JEL Classification: I11, L65.
\end{abstract}

${ }^{*}$ University of Lyon, Lyon, F-69007, France; CNRS, GATE Lyon Saint-Etienne, F-69130, France. Email: houy@gate.cnrs.fr.

${ }^{\dagger}$ University of Lyon, Lyon, F-69007, France; CNRS, GATE Lyon Saint-Etienne, F-69130, France. Email: jelovac@gate.cnrs.fr. 


\section{Introduction}

This paper analyzes how drug approval procedures influence the incentives of pharmaceutical firms to launch new drugs in the presence of international reference pricing. The focus is on the exogenous timing of drug approvals, the endogenous timing of launches and on the regulated pricing of drugs. We leave apart the important issues of quality and safety on the one hand and of incentives to innovate on the other hand, both sensitive to the drug approval regulation.

Before launching a new drug on a market, a pharmaceutical firm must satisfy some regulatory constraints. One important compulsory step is to obtain a marketing authorization (MA). This authorization depends on the proof that the new drug complies with safety, quality and efficacy standards. In the US, the Food and Drug Administration is in charge of approving new drugs. In the EU, four alternative procedures co-exist for drug approval: the centralized procedure, the decentralized procedure, the national procedure and the mutual recognition procedure [Eudralex, 2013]. The centralized procedure allows firms to submit a single application to the European Medicines Agency to obtain a centralized MA valid in all EU countries, Iceland, Liechtenstein and Norway. ${ }^{1}$ The decentralized procedure may be used to obtain a MA in several Member States when the applicant does not yet have a MA in any country. The national procedure is used to obtain a MA in one country at a time or in the initial phase of the mutual recognition procedure. The mutual recognition procedure is used to request a MA in EU countries for products that have already received authorizations in other EU countries.

The distinctive feature between these procedures that motivates our analysis is whether the drug is approved simultaneously in all countries or not. In the case of the EU, only the

\footnotetext{
${ }^{1}$ The centralized procedure is compulsory for all medicines derived from biotechnology and other hightech processes, as well as for human medicines for the treatment of HIV/AIDS, cancer, diabetes, neurodegenerative diseases, auto-immune and other immune dysfunctions, and viral diseases, and for veterinary medicines for use for growth or yield enhancers. The centralized procedure is also open to products that bring a significant therapeutic, scientific or technical innovation, or is in any other respect in the interest of patient or animal health. As a result, the majority of genuinely novel medicines are authorized through the European Medicines Agency.
} 
centralized procedure guarantees a simultaneous MA in all EU countries. In the alternative three non-centralized procedures, new drugs do not necessarily obtain a MA simultaneously in all countries. Once a MA is obtained, a drug producer can start commercializing its new drugs at any time, but without exceeding three years (sunset clause). We show that whether MAs are simultaneous or not can influence how pharmaceutical firms strategically respond to international reference pricing. In particular, it influences whether and when they launch a new drug in different countries where they have a MA.

A second set of regulatory constraints that is crucial when launching a new drug and after, refers to pricing rules. In fact, the system of patents together with the widespread availability of health insurance (public or private) can induce excessively high pharmaceutical prices in the absence of regulation. Therefore, many countries use some regulatory tools to control the expenses related to the consumption of drugs.

One such regulation is the international reference pricing (IRP) in countries. An IRP imposes a price cap based on prices of identical drugs in other reference countries. Almost every EU country use IRPs. The IRP formula varies from one country to another. Some use the lowest price observed in the reference countries while other use an average of the reference prices. Countries can revise prices periodically and they choose to use foreign prices retroactively or not, [Rankin, 2003]. The basket of reference countries varies in size from one country to another. We observe that the sets of reference countries include an increasing number of countries over time, [Leopold et al., 2012]. This regulation typically induces a convergence between international drug prices. Moreover, many authors argue that it gives incentives to pharmaceutical firms to sequentially launch new drugs, initiating the sales in high-price countries, [Varol et al., 2012, among others].

In this article, our research interest is related to three streams of literature, which are, to the best of our knowledge, disconnected from each other. First, concerning the approval of new products, we can mention the existing literature on quality standards. However, as far as we are aware of, there is hardly any mention to the centralization (or the lack thereof) 
of standard settings. Authors rather focus on the important issue of how organizations set their standards where applicants decide to apply [Lerner and Tirole, 2006; Chiao et al., 2007].

Second, closer to our purpose, is the literature on the architecture of organizations, which focuses on the differences between committees, hierarchies and polyarchies [Sah and Stiglitz, 1986, 1988]. Authors interestingly analyze the performance of each type of structure in accepting or rejecting good-quality products and projects. However, they ignore the possible influence of the structure on the strategic decisions of the applicants.

Third, the literature on IRPs is, up to our knowledge, mainly empirical. It repeatedly provides evidence about the link between IRPs, interdependence of prices and timing of new drugs launches. In particular, several authors show that price regulations such as IRPs cause launch delays and even absence of launches in some countries, [Danzon and Epstein, 2008; Danzon et al., 2005; Kyle, 2007; Lanjouw, 2005; Rankin, 2003; Varol et al., 2012]. However, they do not explain why some launches are delayed in time while other launches simply never occur in some countries. [Verniers et al., 2011], analyze launch delays for drugs, considering that launch delays are a regulator's strategic decision rather than a firm's one.

[Houy and Jelovac, 2014] is the only article to theoretically derive the optimal firms' strategy of launch timing under different modalities of IRPs and given some network structure that reflects the IRPs in all countries. It shows that, for a rather flexible network structure (a transitive one), firms respond to IRPs by never launching drugs sequentially if IRPs are retroactive and prices are revised periodically. Instead, under these conditions, firms are better off launching the new drug immediately in countries with a high willingness to pay and never in the remaining ones. Counter-examples are also provided for some specific network structures characterized by a very high connectivity of one country in the network. An implicit assumption in [Houy and Jelovac, 2014] is the absence, or equivalently, simultaneity, of MAs in all countries. 
In the present paper, we relax the assumption of simultaneous MAs in all countries. Still, we continue focusing on retroactive IRPs with periodical price revisions. First, we show that the set of countries in which a firm commercializes a new drug is larger when countries do not approve this new drug simultaneously. Then, we show that a firm's best response to IRPs is to never launch new drugs sequentially as long as the differences in times necessary to obtain a MA between countries are small enough. Therefore, we confirm the main result of [Houy and Jelovac, 2014], for small differences in MA times. Furthermore, we show that a firm's incentives to launch a new drug in one or another country are the same no matter whether the MA times are simultaneous across countries or if the approval times are close enough. However, we show that these incentives can change if the differences between approvals times increase. In particular, it can be optimal for a firm not to launch a new drug in a low-price country if the approval times are close enough between high-price and low-price countries. However, it can be optimal to launch the drug in the low-price countries as well if the latter approve the drug early enough compared to the other countries.

The remaining of the paper is organized as follows. In Section 2, we describe the formal framework. We provide an illustrative example in Section 3. In Section 4, we derive general results on optimal pricing. In Section 5, we analyze the effect of approval times. Section 6 concludes. Proofs are given in the Appendix.

\section{Formal framework}

We consider the optimal price vectors for a monopolistic firm offering a new drug for the international market. The patent that protects any new drug justifies the monopolistic position of the firm. With no lack of generality, we consider that the cost of production for the drug is null. Buyers are countries or the health authorities in each of the countries. Let $N=(1, \ldots, N)$ be the set of countries. ${ }^{2}$ We assume that the drug is sold in all countries

\footnotetext{
${ }^{2}$ With a slight lack a rigor, but with no risk of confusion, $N$ is both the set of countries and its cardinality.
} 
with perfect segmentation. Said differently, there is no parallel imports.

Each country $i$ has a willingness to pay (WTP), $w_{i}$, that is the price above which it is not willing to buy the drug under any circumstances. Let $\left(w_{1}, \ldots, w_{N}\right) \in \mathbb{R}^{+* N}$ be the WTPs for all countries. ${ }^{3}$

Each country $i$ is also characterized by a market size (MS), $\omega_{i}$. This is the quantity the seller can sell in country $i$ if country $i$ buys the drug. Let $\left(\omega_{1}, \ldots, \omega_{N}\right) \in \mathbb{R}^{+*}{ }^{N}$ be the MSs for all countries. ${ }^{4}$

Finally, each country $i$ allows the monopoly to enter its market only after $m_{i} \in \mathbb{N}$ periods corresponding to the time needed for all processes of authorization, application, referring, filing, approval, etc in country $i$. Let $\left(m_{1}, \ldots, m_{N}\right) \in \mathbb{N}$ be the Approval Times (ATs) for all countries.

The problem of the monopolistic seller is to maximize its intertemporal profit over the price vectors $\left(p_{i}^{t}\right)_{i \in N, t \in \mathbb{N}}$ where $\forall i \in N, \forall t \in \mathbb{N}, p_{i}^{t} \in \mathbb{R}^{+}$is the price set in country $i$ at time t. Let $\mathcal{P}$ be the set of all possible price vectors. Notice that, obviously, we allow for prices that would change over time and countries.

We consider that all countries are part of the same complete international reference pricing system, hence all IRPs are complete. ${ }^{5}$ IRPs are retroactive, they are based on the lowest price abroad and prices can be revised over time. Then, given a price vector $\left(p_{i}^{t}\right)_{i \in N, t \in \mathbb{N}} \in \mathcal{P}$, for any period $t$, the demand in country $i$ is $\omega_{i}$ if the following conditions are all met:

1. $t \geq m_{i}$. If this condition is not met, the drug is not approved in country $i$ and cannot enter the market.

2. $p_{i}^{t} \leq w_{i}$. If this condition is not met, the price of the drug in country $i$ is higher than

\footnotetext{
${ }^{3}$ As a general remark, we use superscripts for time indices and subscripts for country indices. $\mathbb{R}^{+}$ denotes the set of all positive real numbers. $\mathbb{R}^{+*}$ denotes the set of all strictly positive real numbers. $\mathbb{N}$ denotes the set of all positive integers.

${ }^{4}$ Notice that, with no loss of generality, we do not consider countries with null WTP or MS. Such countries can just be considered nonexistent by the seller.

${ }^{5}$ For a thorough study of incomplete IRPs, see [Houy and Jelovac, 2014].
} 
the WTP of this country.

3. if $t>0, p_{i}^{t} \leq \min _{i^{\prime} \in N, t^{\prime}<t} p_{i^{\prime}}^{t^{\prime}}$. This condition corresponds to the constraint imposed by the IRPs. We do not explicitly model the bargaining process between the seller and the buyer but consider, in line with what is observed in reality, that country $i$ can impose that the price at which the drug is sold in its territory be not higher than any price ever observed in any country since its IRP is complete (every country references each others' prices when available).

If any of the previous conditions is not met, the quantity sold at time $t$, in country $i$ is null. ${ }^{6}$ For any price vector $P=\left(p_{i}^{t}\right)_{i \in N, t \in \mathbb{N}} \in \mathcal{P}$, we define the set of countries where the drug is sold at time $t$ as $S^{t}(P)$. Formally,

\section{DEFINITION 1}

$\forall P=\left(p_{i}^{t}\right)_{i \in N, t \in \mathbb{N}} \in \mathcal{P}, S^{t}(P)=\left\{i \in N, t \geq m_{i}\right.$ and $p_{i}^{t} \leq w_{i}$ and $\left[t>0 \Rightarrow p_{i}^{t} \leq\right.$ $\left.\left.\min _{i^{\prime} \in N, t^{\prime}<t} p_{i^{\prime}}^{t^{\prime}}\right]\right\}$.

Then, the intertemporal profit earned by the monopolistic seller is given by

$$
\Pi(P)=\sum_{t \in \mathbb{N}} \beta^{t} \sum_{i \in S^{t}(P)} p_{i}^{t} \omega_{i}
$$

where $0<\beta<1$ is the time discount rate. Let $P^{a} \subseteq \mathcal{P}$ be the set of price vectors maximizing the seller's profit,

$$
P^{a}=\arg \max _{P \in \mathcal{P}} \Pi(P)
$$

\section{Illustrative examples}

Let us consider the monopolistic producer of a new drug. We assume that the producer has no influence on the approval procedure, that is, on the ATs. However, the producer can choose whether and when to commercialize the drug in a country. In our examples, two countries have different WTPs for the new drug and different MSs. In order to illustrate

\footnotetext{
${ }^{6}$ We will say that the drug is sold in a country when the quantity sold is strictly positive.
} 
the effect of different ATs on the optimal firm's strategy, we impose that the only difference between the three examples given below lies in the values for the ATs.

\section{EXAMPLE 1}

Let us consider a set of 2 countries: $N=(1,2)$ with $\operatorname{WTPs}\left(w_{1}, w_{2}\right)=(1,3)$, with MSs $\left(\omega_{1}, \omega_{2}\right)=(5,3)$ and with ATs $\left(m_{1}, m_{2}\right)=(0,0)$. Let $\beta=0.9$.

If the firm sells the drug in both countries from the very start, it does so at prices equal to 1 and 3 in Countries 1 and 2, respectively, during the initial period so as to fully extract the countries' surplus. IRPs becomes effective after one period, so that prices are equal to 1 in both countries from then on. Hence, the firm's intertemporal profit is

$$
[(1 \times 5)+(3 \times 3)]+\frac{0.9}{1-0.9} \times[(1 \times 5)+(1 \times 3)]=86
$$

If the firm sells the drug in country 2 only from the start and forever, its intertemporal profit is

$$
\frac{1}{1-0.9} \times(3 \times 3)=90
$$

In this example, the firm is better off selling in country 2 only. In fact, the gains from selling in country 1 are not worth the losses from spreading the low price of country 1 to country 2. Furthermore, according to [Houy and Jelovac, 2014], it is never optimal to sequentially launch the drug under the conditions of Example 1. In particular, there is no reason to start selling the drug in country 1 at a later date for example.

Now consider Example 2 with a slightly larger AT time in country 2.

\section{EXAMPLE 2}

Let us consider a set of 2 countries: $N=(1,2)$ with $\operatorname{WTPs}\left(w_{1}, w_{2}\right)=(1,3)$, with MSs $\left(\omega_{1}, \omega_{2}\right)=(5,3)$ and with ATs $\left(m_{1}, m_{2}\right)=(0,1)$. Let $\beta=0.9$.

Again, it is optimal for the firm to sell in country 2 only. In fact, its intertemporal profit from selling in both countries as soon as the drug is approved, is

$$
(1 \times 5)+\frac{0.9}{1-0.9} \times[(1 \times 5)+(1 \times 3)]=77
$$


If instead, the firm sells in country 2 only and as soon as possible, the firm's intertemporal profit is

$$
\frac{0.9}{1-0.9} \times(3 \times 3)=81
$$

IRPs takes exactly one period of time to be effective. If the firm sells in country 1 from the start, the low price of country 1 spreads to country 2 exactly at the time of approval in country 2. This spreading of the low price would have happened at the same time if country 2 had approved the drug at the initial period. Therefore, the trade-off identified in Example 1 between selling in one additional market and spreading a low price in country 2 applies equally. The only difference with Example 1 is the absence of profit from country 2 in the initial period, no matter whether the firm sells in country 1 or not. In Example 1 , this initial profit from country 2 was equal to 9 , no matter whether there are sales in country 1 or not. Therefore, earning this profit of 9 or not is irrelevant for the comparison. Incentives are equivalent in Examples 1 and 2, and whatever strategy is optimal for the firm in Example 1 continues to be optimal in Example 2.

Last, we consider Example 3 with ATs that are different enough so that the optimal strategy of the firm changes.

\section{EXAMPLE 3}

Let us consider a set of 2 countries: $N=(1,2)$ with $\operatorname{WTPs}\left(w_{1}, w_{2}\right)=(1,3)$, with MSs $\left(\omega_{1}, \omega_{2}\right)=(5,3)$ and with ATs $\left(m_{1}, m_{2}\right)=(0,2)$. Let $\beta=0.9$.

In example 3, if the firm sells in both countries as soon as it can, its intertemporal profit is

$$
(1+0.9) \times(1 \times 5)+\frac{(0.9)^{2}}{1-0.9} \times[(1 \times 5)+(1 \times 3)]=74.3 .
$$

Instead, if the firm sells in country 2 only, it earns

$$
\frac{(0.9)^{2}}{1-0.9} \times(3 \times 3)=72.9
$$

Conversely to the case in Examples 1 and 2, it is now optimal for the firm to sell in both countries as soon as the market authorization is delivered. The basic trade-off 
between sales in one additional market against the spreading of a low price through IRPs is modified in favor of the country with an early market authorization. The reason here is that the gains from selling in an additional market concern a higher number of periods while the losses from spreading a low price through IRPs does not vary.

\section{General results on optimal price vectors}

The purpose of our study is to draw some conclusions about the effect of ATs on the set of countries in which the drug will be launched. In order to do that, we first need to derive some properties about the price vectors.

The following proposition is a generalization in the case with different ATs of a result already stated in [Houy and Jelovac, 2014]. It states that when the drug is launched by the seller in a country, it is never withdrawn from this country afterward.

\section{Proposition 1}

Let $P \in P^{a} . \forall t \in \mathbb{N}, S^{t}(P) \subseteq S^{t+1}(P)$.

Intuitively, for the seller, the effect of launching the drug in a country is to sell more at the potential cost of selling at a lower price in other countries. Since the IRPs consider all past prices, selling at a point in time in a country already sets a reference price for the future. Hence, withdrawing the drug in the future consists only in losing MS.

We can define, for a given optimal price vector $P \in P^{a}, \overline{S(P)}$ as the set of countries in which the drug is launched at some point in time. Formally,

\section{DEFINITION 2}

$\forall P \in P^{a}, \overline{S(P)}=\left\{i \in N, \exists t \in \mathbb{N}, i \in S^{t}(P)\right\}$.

Because the set of countries in which the drug is launched can only grow larger in time, and because the set of countries we consider is finite, there exists a point in time after which, $\overline{S(P)}$ is exactly the set of countries in which the drug is ever sold.

The following proposition states that there is monotonicity in the set of countries in which the drug is sold at each period. Hence, if the drug is sold in period $t$ in country $i$ 
and if country $j$ 's WTP is greater that country i's, then the drug should also be sold in country $j$. Of course, this results is conditional on the approval process to be completed in country $j$.

\section{Proposition 2}

Let $P \in P^{a}$. Let $i \in N, t \in \mathbb{N}$ be such that $i \in S^{t}(P)$. Let $j \in N$ be such that $w_{i} \leq w_{j}$ and $m_{j} \leq t$. Then, $j \in S^{t}(P)$.

Intuitively, if the drug is sold in country $i$ with a lowest WTP than country $j$ 's, then, setting the same price in country $j$ as in country $i$ implies selling larger quantities (after j's AT) without having any effect on future sales and prices through IRPs.

Finally, the following proposition states that for some optimal price vector and for any period $t$, there is no entry in any market in period $t$ if no country has an AT exactly equal to $t$. Then, any launching period corresponds to an AT in a country. Notice that, possibly, launching can occur in country $i$ when market becomes available in country $j \neq i$ (i.e at j's AT).

\section{Proposition 3}

$\exists P \in P^{a}, \forall t \in \mathbb{N},\left[\left\{i \in N, m_{i}=t\right\}=\emptyset\right.$ and $\left.t>0\right] \Rightarrow S^{t-1}(P)=S^{t}(P)$.

Notice that Proposition 3 states that the condition regarding ATs and launching periods is imposed for at least one but not all optimal price vectors. The reason is the following. Consider for the sake of the illustration the following example.

\section{EXAMPLE 4}

Let us consider 2 countries, $N=(1,2)$ with $\operatorname{WTPs}(1,2)$, MSs $(9,10)$ and ATs $(0,0)$. Let $\beta=0.9$.

It is straightforward, following Proposition 3 to check that the following price vector $P=\left(p_{i}^{t}\right)_{i \in N, t \in \mathbb{N}} \in \mathcal{P}$ is optimal if $\forall i \in N, \forall t \in \mathbb{N}, p_{i}^{t}=2$. In this case, $\forall t \in \mathbb{N}, S^{t}(P)=\{2\}$ and $\Pi(P)=200$. However, let us have $P^{\prime}=\left(p^{\prime t}\right)_{i \in N, t \in \mathbb{N}} \in \mathcal{P}$ defined by

$$
\forall i \in N, \forall t \in \mathbb{N}, p_{i}^{\prime t}= \begin{cases}2 & , \text { if } t=0 \\ 2 & , \text { if } t=1 \text { and } i=2 . \\ 1 & , \text { otherwise }\end{cases}
$$


It is straightforward to check that $\Pi\left(P^{\prime}\right)=200$. Hence, $P^{\prime}$ is also optimal with $S^{0}(P)=\{2\}$ and $\forall t>0 \in \mathbb{N}, S^{t}(P)=\{1,2\}$. In this case, the conditions stated in Proposition 3 are not satisfied for $P^{\prime}$. The reason is the following. Example 4 describes a very particular situation where the loss suffered by the seller in terms of price decreasing in country 2 in order to sell in country 1 is exactly equal to the surplus profit earned from increasing the MS. In this particular case, the launching in country 1 can be implemented at any point in time without losing profit and hence is not conditional on the AT in another country. These are the only cases for which Proposition 3 does not generalize to all optimal price vectors.

\section{The effect of Approval Times}

We will now derive some results regarding the sets of countries in which the drug is ever launched and the effect of ATs on this set. First, let us consider the sets of countries in which the drug is ever launched when all ATs are null and the seller is constrained to launch the drug in the same countries at each period. Formally, if $\mathcal{S}^{0}$ is the set of these sets, we have,

$$
\begin{gathered}
\text { Definition } 3 \\
\mathcal{S}^{0}=\arg \max _{S \subseteq N} \sum_{i \in S} w_{i} \omega_{i}+\frac{\beta}{1-\beta}\left(\min _{i \in S} w_{i}\right)\left(\sum_{i \in S} \omega_{i}\right) .
\end{gathered}
$$

The following two propositions show that $\mathcal{S}^{0}$ is exactly the set of sets of countries in which the drug is ever launched when all ATs are null. Then, the constraint that the drug should be launched in the same countries at each period that we considered in order to define $\mathcal{S}^{0}$ is not a binding one.

\section{Proposition 4}

Assume $\forall i \in N, m_{i}=0 . \forall S \in \mathcal{S}^{0}, \exists P \in P^{a}, \overline{S(P)}=S$.

\section{Proposition 5}

Assume $\forall i \in N, m_{i}=0 . \forall P \in P^{a}, \overline{S(P)} \in \mathcal{S}^{0}$. 
The intuition is the same as the one we gave in Example 4. As we stated, in the case where all ATs are null, the only reason why we could have a launch in a country after period 0 is when the decrease in price it induces for the sales in the other countries is exactly compensated by the gain in MS. But then, it is also optimal for the seller to launch the drug in this country from period 0 .

Proposition 6 shows that when ATs are not necessarily all null, the set of countries in which the drug is sold can only be larger than in the case where all ATs are null. Said differently, differences in ATs increase the set of countries in which a new drug is launched.

\section{Proposition 6}

$\forall P \in P^{a}, \exists S \in \mathcal{S}^{0}, S \subseteq \overline{S(P)}$.

The following two propositions generalize Propositions 4 and 5 when all the ATs are either null or unity. Then, $\mathcal{S}^{0}$ is exactly the set of sets of countries in which the drug is ever launched when all ATs are null or when they are all 0 or 1 . Including a 1 period delay in the ATs for some countries has no effect on which countries the seller will choose optimally to ever launch the drug. The reason is that it takes exactly one period of time for prices to spread into the countries where they ever spread when the IRPs are complete.

\section{Proposition 7}

Assume $\left\{t \in \mathbb{N}, \exists i \in N, m_{i}=t\right\}=\{0,1\} . \forall P \in P^{a}, \overline{S(P)} \in \mathcal{S}^{0}$.

\section{Proposition 8}

Assume $\left\{t \in \mathbb{N}, \exists i \in N, m_{i}=t\right\}=\{0,1\} . \forall S \in \mathcal{S}^{0}, \exists P \in P^{a}, \overline{S(P)}=S$.

Now the natural question that is raised by the previous results is the following: if extending the ATs by at most 1 period in some countries does not change the countries in which the drug is launched, would the same result hold for more than one period AT extension? Examples 1 and 3 in Section 3 show that the answer to this question is negative. In Example 1, the product is launched in country 2 only for a profit of 90 (profit of 86 if launched in both countries). In Example 3, the product is launched in both countries for a profit of 74.3 (profit of 72.9 if launched only in country 2). 


\section{Conclusion}

This paper extends [Houy and Jelovac, 2014], considering that drug ATs are not necessarily equal across countries. Concretely, we analyze the influence of drug ATs on the optimal launching strategies of pharmaceutical firms when prices are regulated according to an international reference pricing policy.

We confirm the main result of [Houy and Jelovac, 2014], for drug approvals that are close to each other in time. More precisely, when all drug approvals are either simultaneous or one period of time different, a pharmaceutical firm has no incentive to sequentially launch its new drugs in different countries. Instead, it optimally launches its products in high-WTP countries as soon as they are approved there. It never launches drugs in other countries to avoid spreading a low price to the high-WTP countries through IRPs.

However, as the time differences between drug approvals increase above one period of time, the conclusions drastically change. The firm faces different incentives when deciding whether to launch a new drug in a country or not. In particular, if a low-WTP country delivers a market authorization early enough compared to high-WTP countries, the firm can be better-off commercializing the drug in the low-WTP countries too, even if it spreads a low price to other countries through IRPs. Moreover, we show that the number of countries in which the firm optimally commercializes its products is higher when the differences between market authorization times exceeds one period of time.

We have performed this analysis keeping approval times exogenous. Our results seemingly provide one argument against the centralization of the market authorization procedures if the objective is that drugs be launched in the largest possible set of countries. Hence, we expect that low-WTP countries have an incentive to speed up their market approval procedure to increase their chance of having new drugs on their market. However, this incentive might bring safety issues along if countries accelerate their approval procedures at the expense of an adequate safety testing. Extending our research questions to an endogenous market authorization timing, together with endogenous and costly safety 
controls constitutes an interesting avenue for future research.

We can also think of another extension for future research if relaxing an implicit assumptions of our model. We considered that the marketing authorizations are constraints for pharmaceutical firms only because they impose delays in the launching sequence. Obviously, there also exists a risk dimension in this applied problem. Indeed, submitting a file for approval in a country is risky and the outcome can always be negative. If we consider that this risk is independent across countries and make the time decision to seek approval an endogenous variable, the optimal approval application strategy is obviously to apply for a marketing authorization in all countries as soon as possible since this strategy is one that leads to the least binding constraints for the launching sequence. Then, in this setting, our assumption of exogenous application timing has no strength. However, if we consider more realistically that the approval decision risk is dependent across countries, then, the application sequence is not trivial and interferes with the launching sequence. 


\section{References}

Chiao B, Lerner J, Tirole J. 2007. The Rules of Standard Setting Organizations: an Empirical Analysis. The RAND Journal of Economics 38 (4): 905-930.

Danzon PM, Epstein AJ. 2012. Effects of regulation on drug launch and pricing in interdependent markets. Advances in Health Economics and Health Services Research 23: $35-71$.

Danzon PM, Wang YR, Wang L. 2005. The impact of price regulation on the launch delay of new drugs - evidence from twenty-five major markets in the 1990s. Health Economics 14: 269-292.

Eudralex. 2013. The Rules Governing Medicinal Products in the European Union. Vol. 2A: Procedures for Marketing Authorization (Chapter 1). Directo European Communities Comm. Published by Stationery Office Books.

Houy N, Jelovac I. 2014. Drug launch timing and international reference pricing. Health Economics. Forthcoming.

Kyle MK. 2007. Pharmaceutical price controls and entry strategies. Review of Economics and Statistics 89(1): 88-99.

Lanjouw JO. 2005. Patents, price controls and access to new drugs: How policy affects global market entry, NBER Working Paper 11321.

Leopold C, Vogler S, Mantel-Teeuwisse AK, de Joncheere K, Leufkens HGM, Laing R. 2012. Differences in external price referencing in Europe A descriptive overview. Health Policy 104: 50-60.

Lerner J, Tirole J. 2006. A Model of Forum Shopping. American Economic Review 96(4): 1091-1113. 
Rankin PJ, Bell GK, Wilsdon T. 2003. The pharmaceutical Pricing Compendium (1st edn). Urch Publishing: London.

Sah RK, Stiglitz JE. 1986. The Architecture of Economic Systems: Hierarchies and Polyarchies. American Economic Review 76(4): 716-27.

Sah RK, Stiglitz JE. 1988. Committees, Hierarchies and Polyarchies. Economic Journal 98(391): 451-70.

Varol N, Costa-Font J, McGuire A. 2012. Does adoption of pharmaceutical innovation respond to changes in the regulatory environment?. Applied Economic Perspectives and Policy 34(3): 531-553.

Verniers I, Stremersch S, Croux C. 2011. The global entry of new pharmaceuticals: A joint investigation of launch window and price. International Journal of Research in Marketing 28: 295-308. 


\section{A Proofs}

Let us set the following definitions:

- let $\bar{w}=\max _{i \in N} w_{i}$ be the largest WTP for all countries,

- let $\bar{m}=\max _{i \in N} m_{i}$ be the maximum AT for all countries,

- let $\forall A \subseteq N, w_{A}=\min _{i \in A} w_{i}$ be the minimum WTP for the subset of countries in $A$.

\section{LEMMA 1}

Let $P \in P^{a} . \exists t \in \mathbb{N}, S^{t}(P) \neq \emptyset$.

Proof of Lemma 1: Let us have $\epsilon \in \mathbb{R}$ such that $0<\epsilon<w_{N}$. Let us define $P^{\prime}=$ $\left({p^{\prime}}_{i}^{t}\right)_{i \in N, t \in \mathbb{N}} \in \mathcal{P}$ be such that $\forall i \in N, \forall t \in \mathbb{N}, p^{\prime t}{ }_{i}=\epsilon$. By definition, $\forall i \in N, \forall t \geq m_{i}, i \in$ $S^{t}\left(P^{\prime}\right)$ and then $\Pi\left(P^{\prime}\right)>0$. By definition, $\forall P \in P^{a}, \Pi(P) \geq \Pi\left(P^{\prime}\right)>0$.

\section{LEMMA 2}

Let $P=\left(p_{i}^{t}\right)_{i \in N, t \in \mathbb{N}} \in P^{a} . \forall t \in \mathbb{N}, \forall i \in N, p_{i}^{t}>0$.

Proof of Lemma 2: Assume it is not the case. Let $T \in \mathbb{N}$ be such that $\exists i \in N, p_{i}^{T}=0$.

Let us have $\epsilon \in \mathbb{R}^{+*}$ such that $0<\epsilon<w_{N}$. Let $P^{\prime}=\left({p^{\prime}}_{i^{\prime}}^{t^{\prime}}\right)_{i^{\prime} \in N, t^{\prime} \in \mathbb{N}} \in \mathcal{P}$ be defined as:

$$
\forall i^{\prime} \in N, \forall t^{\prime} \in \mathbb{N}, p_{i^{\prime}}^{t^{\prime}}= \begin{cases}\epsilon & , \text { if } p_{i^{\prime}}^{t^{\prime}}<\epsilon \\ p_{i^{\prime}}^{t^{\prime}} & , \text { otherwise }\end{cases}
$$

Let $i \in S^{0}(P)$. By definition, $p_{i}^{t} \leq w_{i}$. Then, since $\epsilon<w_{N}, p_{i}^{\prime t} \leq w_{i}$ which implies $i \in S^{0}\left(P^{\prime}\right)$.

Let $i \in S^{t}(P)$ with $t>0$. By definition, $p_{i}^{t} \leq w_{i}$ and $p_{i}^{t} \leq \min _{i^{\prime} \in N, t^{\prime}<t} p_{i^{\prime}}^{t^{\prime}}$. Then, since $\epsilon<w_{N}, p_{i}^{\prime t} \leq w_{i}$. Moreover, it is straightforward to check that $p_{i}^{\prime t} \leq \min _{i^{\prime} \in N, t^{\prime}<t}{p^{\prime}}_{i}^{t}$. Hence, $i \in S^{t}\left(P^{\prime}\right)$.

$\Pi(P)=\sum_{t \leq T} \beta^{t} \sum_{i \in S^{t}(P)} p_{i}^{t} \omega_{i}+\sum_{t>T} \beta^{t} \sum_{i \in S^{t}(P)} p_{i}^{t} \omega_{i}$. By what we showed, $\sum_{t \leq T} \beta^{t} \sum_{i \in S^{t}(P)} p_{i}^{t} \omega_{i} \leq$ $\sum_{t \leq T} \beta^{t} \sum_{i \in S^{t}\left(P^{\prime}\right)} p_{i}^{\prime t} \omega_{i}$ and it is straightforward to check that $\sum_{t>T} \beta^{t} \sum_{i \in S^{t}(P)} p_{i}^{t} \omega_{i}=0<\sum_{t>T} \beta^{t} \sum_{i \in S^{t}\left(P^{\prime}\right)} p_{i}^{\prime t} \omega_{i}$. 
Then, $\Pi\left(P^{\prime}\right)>\Pi(P)$ which contradicts the assumption that $P \in P^{a}$.

\section{DEFINITION 4}

Let $P=\left(p_{i}^{t}\right)_{i \in N, t \in \mathbb{N}} \in \mathcal{P}, M P_{i}^{t}(P) \in \mathbb{R}^{+}$is defined as follows

$$
M P_{i}^{t}(P)=\left\{\begin{array}{ll}
\min \left(w_{i}, \min _{i^{\prime} \in N, t^{\prime}<t} p_{i^{\prime}}^{t^{\prime}}\right) & , \text { if } t>0 \\
w_{i} & , \text { if } t=0
\end{array} .\right.
$$

Proof of Proposition 1: Assume it is not the case. Let $i \in N, t \in \mathbb{N}$ be such that $i \in S^{t}(P)$ and $i \notin S^{t+1}(P)$. Let $P^{\prime}=\left({p^{\prime}}_{i^{\prime}}^{t^{\prime}}\right)_{i^{\prime} \in N, t^{\prime} \in \mathbb{N}} \in \mathcal{P}$ be defined as:

$$
\forall i^{\prime} \in N, \forall t^{\prime} \in \mathbb{N}, p_{i^{\prime}}^{t^{\prime}}=\left\{\begin{array}{ll}
\min _{i^{\prime \prime} \in N, t^{\prime \prime}<t+1} p_{t^{\prime \prime}}^{i^{\prime \prime}} & , \text { if } i^{\prime}=i \text { and } t^{\prime}=t+1 \\
p_{i^{\prime}}^{t^{\prime}} & , \text { otherwise }
\end{array} .\right.
$$

By definition, $\forall i^{\prime} \in N, \forall t^{\prime} \leq t+1, M P_{i^{\prime}}^{t^{\prime}}(P)=M P_{i^{\prime}}^{t^{\prime}}\left(P^{\prime}\right)$.

$i \in S^{t}(P)$ implies $p_{i}^{t} \leq w_{i}$ and $t \geq m_{i}$. Hence, $i \notin S^{t+1}(P) \operatorname{implies} p_{i}^{t+1}>\min _{i^{\prime \prime} \in N, t^{\prime \prime}<t+1} p_{t^{\prime \prime}}^{i^{\prime \prime}}=$

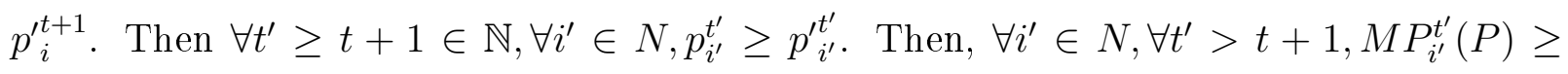
$M P_{i^{\prime}}^{t^{\prime}}\left(P^{\prime}\right)$

Moreover, $\forall t^{\prime}>t+1$,

$$
\begin{aligned}
& \min _{i^{\prime \prime} \in N, t^{\prime \prime}<t^{\prime}} p_{i^{\prime \prime}}^{\prime t^{\prime \prime}}= \\
& \min \left(\min _{i^{\prime \prime} \in N, t^{\prime \prime}<t+1} p_{i^{\prime \prime}}^{\prime t^{\prime \prime}}, \min _{i^{\prime \prime} \in N} p_{i^{\prime \prime}}^{\prime t+1}, \min _{i^{\prime \prime} \in N, t^{\prime}>t^{\prime \prime}>t+1} p_{i^{\prime \prime}}^{\prime t^{\prime \prime}}\right)= \\
& \min \left(\min _{i^{\prime \prime} \in N, t^{\prime \prime}<t+1} p_{i^{\prime \prime}}^{t^{\prime \prime}}, \min _{i^{\prime \prime} \in N} p_{i^{\prime \prime}}^{t+1}, \min _{i^{\prime \prime} \in N, t^{\prime}>t^{\prime \prime}>t+1} p_{i^{\prime \prime}}^{t^{\prime \prime}}\right)= \\
& \min \left(\min _{i^{\prime \prime} \in N, t^{\prime \prime}<t+1} p_{i^{\prime \prime}}^{t^{\prime \prime}} \min _{i^{\prime \prime} \in N \backslash\{i\}} p_{i^{\prime \prime}}^{\prime t+1}, p_{i}^{\prime t+1}, \min _{i^{\prime \prime} \in N, t^{\prime}>t^{\prime \prime}>t+1} p_{i^{\prime \prime}}^{t^{\prime \prime}}\right)= \\
& \min \left(\min _{i^{\prime \prime} \in N, t^{\prime \prime}<t+1} p_{i^{\prime \prime}}^{t^{\prime \prime}}, \min _{i^{\prime \prime} \in N \backslash\{i\}} p_{i^{\prime \prime}}^{t+1}, \min _{i^{\prime \prime} \in N, t^{\prime}>t^{\prime \prime}>t+1} p_{i^{\prime \prime}}^{t^{\prime \prime}}\right) \geq \\
& \min _{i^{\prime \prime} \in N, t^{\prime \prime}<t^{\prime}} p_{i^{\prime \prime}}^{t^{\prime \prime}}
\end{aligned}
$$

Hence, $\forall i^{\prime} \in N, \forall t^{\prime}>t+1, M P_{i^{\prime}}^{t^{\prime}}(P) \leq M P_{i^{\prime}}^{t^{\prime}}\left(P^{\prime}\right)$.

Then, $\forall i^{\prime} \in N, \forall t^{\prime}>t+1, M P_{i^{\prime}}^{t^{\prime}}(P)=M P_{i^{\prime}}^{t^{\prime}}\left(P^{\prime}\right)$.

Then, $\forall i^{\prime} \in N, \forall t^{\prime} \in \mathbb{N}, M P_{i^{\prime}}^{t^{\prime}}(P)=M P_{i^{\prime}}^{t^{\prime}}\left(P^{\prime}\right)$. Hence, $\forall i^{\prime} \in N, \forall t^{\prime} \in \mathbb{N},\left[i^{\prime} \neq i\right.$ or $t^{\prime} \neq$ $t] \Rightarrow\left[i^{\prime} \in S^{t^{\prime}}\left(P^{\prime}\right) \Leftrightarrow i^{\prime} \in S^{t^{\prime}}(P)\right]$. 
$i \in S^{t}(P)$ implies $p_{i}^{t} \leq w_{i}$ and $t \geq m_{i} . p_{i}^{t} \leq w_{i}$ implies $p_{i}^{\prime t+1} \leq w_{i}$. Then, by definition, $p_{i}^{\prime t+1} \leq M P_{i}^{t+1}\left(P^{\prime}\right)$. Then, $i \in S^{t+1}\left(P^{\prime}\right)$.

Then, by Lemma $2, \Pi\left(P^{\prime}\right)>\Pi(P)$ which contradicts the fact that $P \in P^{a}$.

\section{LEMMA 3}

Let $P=\left(p_{i}^{t}\right)_{i \in N, t \in \mathbb{N}} \in P^{a} . \forall i \in S^{t}(P), \forall t \in \mathbb{N}, p_{i}^{t}=M P_{i}^{t}(P)$.

Proof of Lemma 3: Assume it is not the case. Let $i \in N$ and $t \in \mathbb{N}$ be such that $p_{i}^{t} \neq M P_{i}^{t}(P)$. By definition, if $p_{i}^{t}>M P_{i}^{t}(P)$, then, $i \notin S^{t}(P)$ contradicting the assumptions. Then, assume $p_{i}^{t}<M P_{i}^{t}(P)$. Let $P^{\prime}=\left(p_{i^{\prime}}^{\prime t^{\prime}}\right)_{i^{\prime} \in N, t^{\prime} \in \mathbb{N}} \in \mathcal{P}$ be defined as:

$$
\forall i^{\prime} \in N, \forall t^{\prime} \in \mathbb{N}, p^{\prime t^{\prime}}{ }_{i^{\prime}}^{\prime}= \begin{cases}M P_{i}^{t}(P) & , \text { if } i^{\prime}=i \text { and } t^{\prime}=t \\ p_{i^{\prime}}^{t^{\prime}} & , \text { otherwise }\end{cases}
$$

By definition, since we assumed $p_{i}^{t}<M P_{i}^{t}(P)=p_{i}^{\prime t}, \forall i^{\prime} \in N, \forall t^{\prime} \in \mathbb{N}, M P_{i^{\prime}}^{t^{\prime}}(P) \leq$ $M P_{i^{\prime}}^{t^{\prime}}\left(P^{\prime}\right)$ and hence, $\forall i^{\prime} \in N, \forall t^{\prime} \in \mathbb{N},\left[i^{\prime} \neq i\right.$ or $\left.t^{\prime} \neq t\right] \Rightarrow\left[i^{\prime} \in S^{t^{\prime}}(P) \Rightarrow i^{\prime} \in S^{t^{\prime}}\left(P^{\prime}\right)\right]$.

By definition, $i \in S^{t}(P)$ implies $t \geq m_{i}$. Besides, by definition of $P^{\prime}, p^{\prime t} \leq M P_{i}^{t}(P)$. Hence, $i \in S^{t^{\prime}}\left(P^{\prime}\right)$.

Hence, it is straightforward to check that $\Pi\left(P^{\prime}\right)>\Pi(P)$, contradicting the assumption stating $P \in P^{a}$.

\section{LEMMA 4}

Let $P=\left(p_{i}^{t}\right)_{i \in N, t \in \mathbb{N}} \in P^{a} . \forall i \in S^{0}(P), p_{i}^{0}=w_{i}$.

Proof of Lemma 4: By Lemma 3.

Proof of Proposition 2: Assume it is not the case, i.e. $j \notin S^{t}(P)$. Let $P^{\prime}=$ $\left(p^{\prime \prime i^{\prime}}\right)_{i^{\prime} \in N, t^{\prime} \in \mathbb{N}} \in \mathcal{P}$ be defined as:

$$
\forall i^{\prime} \in N, \forall t^{\prime} \in \mathbb{N}, p_{i^{\prime}}^{t^{\prime}}= \begin{cases}M P_{j}^{t}(P) & , \text { if } i^{\prime}=j \text { and } t^{\prime}=t \\ p_{i^{\prime}}^{t^{\prime}} & , \text { otherwise }\end{cases}
$$


By definition, $\forall i^{\prime} \in N, \forall t^{\prime} \leq t, M P_{i^{\prime}}^{t^{\prime}}(P)=M P_{i^{\prime}}^{t^{\prime}}\left(P^{\prime}\right)$.

Moreover, since by assumption, $m_{j} \leq t, j \notin S^{t}(P)$ implies $p_{j}^{t}>M P_{j}^{t}(P)$. Hence, $p_{j}^{t}>p^{\prime t}{ }_{j}$. Then, by definition, $\forall i^{\prime} \in N, \forall t^{\prime}>t, M P_{i^{\prime}}^{t^{\prime}}(P) \geq M P_{i^{\prime}}^{t^{\prime}}\left(P^{\prime}\right)$.

Moreover, $\forall t^{\prime}>t$,

$$
\begin{aligned}
& \min _{i^{\prime \prime} \in N, t^{\prime \prime}<t^{\prime}} p_{i^{\prime \prime}}^{t^{\prime \prime}}= \\
& \min \left(\min _{i^{\prime \prime} \in N, t^{\prime \prime}<t} p_{i^{\prime \prime}}^{\prime t^{\prime \prime}} \min _{i^{\prime \prime} \in N} p_{i^{\prime \prime}}^{\prime t} \min _{i^{\prime \prime} \in N, t^{\prime}>t^{\prime \prime}>t} p_{i^{\prime \prime}}^{\prime t^{\prime \prime}}\right)= \\
& \min \left(\min _{i^{\prime \prime} \in N, t^{\prime \prime}<t} p_{i^{\prime \prime}}^{t^{\prime \prime}} \min _{i^{\prime \prime} \in N} p_{i^{\prime \prime}}^{\prime t}, \min _{i^{\prime \prime} \in N, t^{\prime}>t^{\prime \prime}>t} p_{i^{\prime \prime}}^{t^{\prime \prime}}\right)= \\
& \min \left(\min _{i^{\prime \prime} \in N, t^{\prime \prime}<t} p_{i^{\prime \prime}}^{t^{\prime \prime}} \min _{i^{\prime \prime} \in N \backslash\{i, j\}} p_{i^{\prime \prime}}^{t}, p_{j}^{\prime t}, p_{i}^{\prime t}{ }_{i^{\prime \prime} \in N, t^{\prime}>t^{\prime \prime}>t+1}^{\prime} p_{i^{\prime \prime}}^{t^{\prime \prime}}\right)= \\
& \min \left(\min _{i^{\prime \prime} \in N, t^{\prime \prime}<t} p_{i^{\prime \prime}}^{t^{\prime \prime}} \min _{i^{\prime \prime} \in N \backslash\{i, j\}} p_{i^{\prime \prime}}^{t}, p^{\prime t}, p_{i}^{t}, \min _{i^{\prime \prime} \in N, t^{\prime}>t^{\prime \prime}>t+1} p_{i^{\prime \prime}}^{t^{\prime \prime}}\right) \text {. }
\end{aligned}
$$

However, since $w_{i} \leq w_{j}, M P_{i}^{t}(P) \leq M P_{j}^{t}(P)$. By Lemma 3 , since $i \in S^{t}(P), p_{i}^{t}=M P_{i}^{t}(P)$. Then, $p_{i}^{t}=M P_{i}^{t}(P) \leq M P_{j}^{t}(P)={p^{\prime}}_{j}^{t}$. Then,

$$
\begin{gathered}
\min _{i^{\prime \prime} \in N, t^{\prime \prime}<t^{\prime}} p_{i^{\prime \prime}}^{t^{\prime \prime}}= \\
\min \left(\min _{i^{\prime \prime} \in N, t^{\prime \prime}<t} p_{i^{\prime \prime}}^{t^{\prime \prime}} \min _{i^{\prime \prime} \in N \backslash\{i, j\}} p_{i^{\prime \prime}}^{t}, p_{i}^{t}, \min _{i^{\prime \prime} \in N, t^{\prime \prime}<t^{\prime}} p_{i^{\prime \prime}}^{t^{\prime \prime}} .\right. \\
t^{\prime}>t^{\prime \prime}>t+1 \\
\left.i_{i^{\prime \prime}}^{t^{\prime \prime}}\right) \geq
\end{gathered}
$$

Hence, $\forall i^{\prime} \in N, \forall t^{\prime}>t, M P_{i^{\prime}}^{t^{\prime}}(P) \leq M P_{i^{\prime}}^{t^{\prime}}\left(P^{\prime}\right)$.

Then, $\forall i^{\prime} \in N, \forall t^{\prime}>t, M P_{i^{\prime}}^{t^{\prime}}(P)=M P_{i^{\prime}}^{t^{\prime}}\left(P^{\prime}\right)$. Hence, $\forall i^{\prime} \in N, \forall t^{\prime} \in \mathbb{N},\left[i^{\prime} \neq j\right.$ or $t^{\prime} \neq$ $t] \Rightarrow\left[i^{\prime} \in S^{t^{\prime}}\left(P^{\prime}\right) \Leftrightarrow i^{\prime} \in S^{t^{\prime}}(P)\right]$.

Since by assumption, $t \geq m_{j}$ and by definition of $P^{\prime},{p^{\prime}}_{j}^{t} \leq M P_{j}^{t}(P)=M P_{j}^{t}\left(P^{\prime}\right)$, then, $j \in S^{t}\left(P^{\prime}\right)$.

Then, using Lemma $2, \Pi\left(P^{\prime}\right)>\Pi(P)$ which contradicts the fact that $P \in P^{a}$.

In the following, we will use an arbitrary strictly positive number $\delta \in \mathbb{R}^{+*}$.

\section{DEFINITION 5}

Let $P=\left(p_{i}^{t}\right)_{i \in N, t \in \mathbb{N}} \in P^{a} . \tilde{P}=\left(\tilde{p}_{i}^{t}\right)_{i \in N, t \in \mathbb{N}} \in \mathcal{P}$ is defined as:

$$
\forall i^{\prime} \in N, \forall t^{\prime} \in \mathbb{N}, \tilde{p}_{i^{\prime}}^{t^{\prime}}=\left\{\begin{array}{ll}
p_{i^{\prime}}^{t^{\prime}} & , \text { if } i^{\prime} \in S^{t^{\prime}}(P) \\
\bar{w}+\delta & , \text { if } i^{\prime} \notin S^{t^{\prime}}(P)
\end{array} .\right.
$$




\section{LEMMA 5}

Let $\forall P \in P^{a}, \forall t \in \mathbb{N}, S^{t}(\tilde{P})=S^{t}(P)$.

Proof of Lemma 5: $\quad$ Let $P=\left(p_{i}^{t}\right)_{i \in N, t \in \mathbb{N}} \in P^{a}$. By definition, $\tilde{P}=\left(\tilde{p}_{i^{\prime}}^{t^{\prime}}\right)_{i^{\prime} \in N, t^{\prime} \in \mathbb{N}} \in \mathcal{P}$ satisfies

$$
\forall i^{\prime} \in N, \forall t^{\prime} \in \mathbb{N}, \tilde{p}_{i^{\prime}}^{t^{\prime}}=\left\{\begin{array}{ll}
p_{i^{\prime}}^{t^{\prime}} & , \text { if } i^{\prime} \in S^{t^{\prime}}(P) \\
\bar{w}+\delta & , \text { if } i^{\prime} \notin S^{t^{\prime}}(P)
\end{array} .\right.
$$

Let $i \in N, t \in \mathbb{N}$ such that $i \in S^{t}(P)$. Then, by definition, $t \geq m_{i}, p_{i}^{t} \leq w_{i}$ and hence $\tilde{p}_{i}^{t} \leq w_{i}$. Then, if $t=0, i \in S^{t}(\tilde{P})$. Assume $t>0$. $i \in S^{t}(P)$ implies

$$
\begin{gathered}
p_{i}^{t}=\tilde{p}_{i}^{t} \leq \min _{i^{\prime} \in N, t^{\prime}<t}\left(p_{i^{\prime}}^{t^{\prime}}, w_{i}\right) \\
\tilde{p}_{i}^{t} \leq \min _{t^{\prime}<t}\left(\min _{i^{\prime} \in S^{t^{\prime}}(P)} p_{i^{\prime}}^{t^{\prime}}, \min _{i^{\prime} \notin S^{t^{\prime}}(P)} p_{i^{\prime}}^{t^{\prime}}, w_{i}\right)=\min _{t^{\prime}<t}\left(\min _{i^{\prime} \in S^{t^{\prime}}(P)} \tilde{p}_{i^{\prime}}^{t^{\prime}}, \min _{i^{\prime} \notin S^{t^{\prime}}(P)} p_{i^{\prime}}^{t^{\prime}}, w_{i}\right) \\
\tilde{p}_{i}^{t} \leq \min _{t^{\prime}<t}\left(\min _{i^{\prime} \in S^{t^{\prime}}(P)} \tilde{p}_{i^{\prime}}^{t^{\prime}}, w_{i}\right)=\min _{t^{\prime}<t}\left(\min _{i^{\prime} \in S^{t^{\prime}}(P)} \tilde{p}_{i^{\prime}}^{t^{\prime}}, \bar{w}+\delta, w_{i}\right) \\
\tilde{p}_{i}^{t} \leq \min _{t^{\prime}<t, i^{\prime} \in N}\left(\tilde{p}_{i^{\prime}}^{t^{\prime}}, w_{i}\right)
\end{gathered}
$$

Then, since $t \geq m_{i}, i \in S^{t}(\tilde{P})$.

Let $i \in N, t \in \mathbb{N}$ be such that $i \notin S^{t}(P)$. Then, by definition, $\tilde{p}_{i}^{t}=\bar{w}+\delta>w_{i}$ which implies $i \notin S^{t}(\tilde{P})$.

\section{LEMMA 6}

Let $\forall P \in P^{a}, \tilde{P} \in P^{a}$.

Proof of Lemma 6: Follows directly from the definition of $\tilde{P}$ and Lemma 5.

\section{LEMMA 7}

$\forall P=\left(p_{i}^{t}\right)_{i \in N, t \in \mathbb{N}} \in P^{a}, \forall i \in N, \forall t \in \mathbb{N}$,

1. $t=0 \Rightarrow\left[i \in S^{t}(P) \Rightarrow p_{i}^{t}=w_{i}\right]$,

2. $t>0 \Rightarrow\left[i \in S^{t}(P) \Rightarrow p_{i}^{t}=\min \left(w_{i}, \min _{t^{\prime}<t, i^{\prime} \in S^{t^{\prime}}(P)} w_{i^{\prime}}\right)\right]$. 
Proof of Lemma 7: 1 follows directly from Lemma 3.

Let us prove 2. By Lemma 6, $\tilde{P} \in P^{a}$. Then, by Lemma $3, \forall t \in \mathbb{N}, \forall i \in N, i \in S^{t}(\tilde{P}) \Rightarrow$ $\tilde{p}_{i}^{t}=M P_{i}^{t}(\tilde{P})$. By recursivity, it is straightforward to check that $\forall t \in \mathbb{N}, \forall i \in N, M P_{i}^{t}(\tilde{P})=$ $\min \left(w_{i}, \min _{t^{\prime}<t, i^{\prime} \in S^{t^{\prime}}(\tilde{P})} w_{i^{\prime}}\right)$. By Lemma $5, \forall t \in \mathbb{N}, S^{t}(\tilde{P})=S^{t}(P)$. Moreover, by definition, $\forall t \in \mathbb{N}, \forall i \in N, i \in S^{t}(P) \Rightarrow p_{i}^{t}=\tilde{p}_{i}^{t}$. Then, $\forall t \in \mathbb{N}, \forall i \in N, i \in S^{t}(P) \Rightarrow p_{t}^{i}=\tilde{p}_{i}^{t}=$ $M P_{i}^{t}(\tilde{P})=\min \left(w_{i}, \min _{t^{\prime}<t, i^{\prime} \in S^{t^{\prime}}(P)} w_{i^{\prime}}\right)$.

\section{LEMMA 8}

$\exists P=\left(p_{i}^{t}\right)_{i \in N, t \in \mathbb{N}} \in P^{a}, \forall i \in N, \forall t \in \mathbb{N}$,

1. $i \notin S^{t}(P) \Rightarrow p_{i}^{t}=\bar{w}+\delta$,

2. $t=0 \Rightarrow\left[i \in S^{t}(P) \Rightarrow p_{i}^{t}=w_{i}\right]$,

3. $t>0 \Rightarrow\left[i \in S^{t}(P) \Rightarrow p_{i}^{t}=\min \left(w_{i}, \min _{t^{\prime}<t, i^{\prime} \in S^{t^{\prime}}(P)} w_{i^{\prime}}\right)\right]$.

Proof of Lemma 8: Let $P \in P^{a}$. By Lemma 6, $\tilde{P} \in P^{a}$. Then, by Lemma 7, $\tilde{P}$ satisfies 2 and 3 . Moreover, by definition, $\tilde{P}$ satisfies 1 .

\section{DEFINITION 6}

Let $P^{*} \subseteq P^{a}$ be the subset of optimal price vectors such that $\forall P \in P^{*}$,

1. $i \notin S^{t}(P) \Rightarrow p_{i}^{t}=\bar{w}+\delta$,

2. $t=0 \Rightarrow\left[i \in S^{t}(P) \Rightarrow p_{i}^{t}=w_{i}\right]$,

3. $t>0 \Rightarrow\left[i \in S^{t}(P) \Rightarrow p_{i}^{t}=\min \left(w_{i}, \min _{t^{\prime}<t, i^{\prime} \in S^{t^{\prime}}(P)} w_{i^{\prime}}\right)\right]$.

\section{LEMMA 9}

$P^{*} \neq \emptyset$.

Proof of Lemma 9: By Lemma 8. 


\section{LEMMA 10}

$\forall P \in P^{*}, \exists P^{\prime} \in P^{*}, \forall t \in \mathbb{N}, t>\bar{m} \Rightarrow S^{t-1}\left(P^{\prime}\right)=S^{t}\left(P^{\prime}\right)=\overline{S(P)}$.

Proof of Lemma 10: Let $P \in P^{*} \subseteq P^{a}$. By definition, $P$ satisfies $\forall i \in N, \forall t \in \mathbb{N}$,

- $i \notin S^{t}(P) \Rightarrow p_{i}^{t}=\bar{w}+\delta$,

- $t=0 \Rightarrow\left[i \in S^{t}(P) \Rightarrow p_{i}^{t}=w_{i}\right]$

- $t>0 \Rightarrow\left[i \in S^{t}(P) \Rightarrow p_{i}^{t}=\min \left(w_{i}, \min _{t^{\prime}<t, i^{\prime} \in S^{t^{\prime}}(P)} w_{i^{\prime}}\right)\right]$.

Let $T>\bar{m}$ be the latest period for which $S^{T-1}(P) \neq S^{T}(P)$. If $T$ is not defined, the proof is complete. By Proposition 1, $S^{T-1}(P) \subset S^{T}(P)$. Let us define $A=S^{T-1}(P) \backslash S^{T}(P) \neq \emptyset$. Let $P^{\prime}=\left(p_{i^{\prime}}^{t^{\prime}}\right)_{i^{\prime} \in N, t^{\prime} \in \mathbb{N}} \in \mathcal{P}$ be defined as:

$$
\forall i^{\prime} \in N, \forall t^{\prime} \in \mathbb{N}, p_{i^{\prime}}^{t^{\prime}}= \begin{cases}w_{i^{\prime}} & , \text { if } i^{\prime} \in A \text { and } t^{\prime}=T-1 \\ \min _{i \in S^{T}(P)} w_{i} & , \text { if } i^{\prime} \in S^{T}(P) \text { and } t^{\prime}=T \\ p_{i^{\prime}}^{t^{\prime}} & , \text { otherwise }\end{cases}
$$

It is straightforward to check that

$$
\begin{gathered}
\Pi(P)-\Pi\left(P^{\prime}\right)= \\
\left(\beta^{T}-\beta^{T-1}\right)\left(\sum_{i \in A} w_{i} \omega_{i}\right) \\
+\beta^{T}\left(w_{S^{T-1}(P)}-w_{S^{T}(P)}\right) \sum_{i \in S^{T-1}(P)} \omega_{i} \\
-\beta^{T} w_{S^{T}(P)} \sum_{i \in A} \omega_{i} .
\end{gathered}
$$

Moreover, $P \in P^{a}$ implies $\Pi(P)-\Pi\left(P^{\prime}\right) \geq 0$. Then,

$$
\begin{array}{r}
\sum_{i \in A} w_{i} \omega_{i} \leq \frac{\beta}{1-\beta}\left[\left(w_{S^{T-1}(P)}-w_{S^{T}(P)}\right)\left(\sum_{i \in S^{T-1}(P)} \omega_{i}\right)\right. \\
\left.-w_{S^{T}(P)}\left(\sum_{i \in A} \omega_{i}\right)\right] .
\end{array}
$$


Now, let $P^{\prime \prime}=\left(p^{\prime \prime} t^{\prime}{ }^{\prime}\right)_{i^{\prime} \in N, t^{\prime} \in \mathbb{N}} \in \mathcal{P}$ be defined as:

$$
\forall i^{\prime} \in N, \forall t^{\prime} \in \mathbb{N}, p^{\prime \prime t^{\prime}}{ }_{i^{\prime}}^{\prime}= \begin{cases}\bar{w}+\delta & , \text { if } i^{\prime} \in A \text { and } t^{\prime} \geq T \\ w_{S^{T-1}(P)} & , \text { if } i^{\prime} \in S^{T-1}(P) \text { and } t^{\prime} \geq T+1 . \\ p_{i^{\prime}}^{t^{\prime}} & , \text { otherwise }\end{cases}
$$

It is straightforward to check that

$$
\begin{gathered}
\Pi(P)-\Pi\left(P^{\prime \prime}\right)= \\
\beta^{T}\left(\sum_{i \in A} w_{i} \omega_{i}\right) \\
+\frac{\beta^{T+1}}{1-\beta}\left(\sum_{i \in S^{T}(P)} w_{S^{T}(P)} \omega_{i}-\sum_{i \in S^{T-1}(P)} w_{S^{T-1}(P)} \omega_{i}\right)
\end{gathered}
$$

Moreover, $P \in P^{a}$ implies $\Pi(P)-\Pi\left(P^{\prime \prime}\right) \geq 0$. Then,

$$
\begin{array}{r}
\sum_{i \in A} w_{i} \omega_{i} \geq \frac{\beta}{1-\beta}\left[\left(w_{S^{T-1}(P)}-w_{S^{T}(P)}\right)\left(\sum_{i \in S^{T-1}(P)} \omega_{i}\right)\right. \\
\left.-w_{S^{T}(P)}\left(\sum_{i \in A} \omega_{i}\right)\right] .
\end{array}
$$

Using Equations 1 and 2, we have

$$
\begin{aligned}
\sum_{i \in A} w_{i} \omega_{i}=\frac{\beta}{1-\beta} & {\left[\left(w_{S^{T-1}(P)}-w_{S^{T}(P)}\right)\left(\sum_{i \in S^{T-1}(P)} \omega_{i}\right)\right.} \\
& \left.-w_{S^{T}(P)}\left(\sum_{i \in A} \omega_{i}\right)\right] .
\end{aligned}
$$

And then, $\Pi(P)=\Pi\left(P^{\prime}\right)$. Then, $P^{\prime} \in P^{a}$. Moreover, it is straightforward to check that $P^{\prime} \in P^{*}$ and $\overline{S\left(P^{\prime}\right)}=\overline{S(P)}$. Let $T^{\prime}>\bar{m}$ be the latest period for which $S^{T-1}\left(P^{\prime}\right) \neq S^{T}\left(P^{\prime}\right)$. If $T^{\prime}$ is not defined, the proof is complete. If $T^{\prime}<T$ is defined, repeat the previous steps of the proof a finite number of times until $T^{\prime}$ is not defined.

\section{LEMMA 11}

$\exists P \in P^{*}, \forall t \in \mathbb{N},\left[\left\{i \in N, m_{i}=t\right\}=\emptyset\right.$ and $\left.t>0\right] \Rightarrow S^{t-1}(P)=S^{t}(P)$. 
Proof of Lemma 11: Let us define $P^{* *}=\left\{P \in P^{*}, \forall t>\bar{m}, S^{t-1}(P)=S^{t}(P)\right\}$. By Lemmas 9 and 10, $P^{* *} \neq \emptyset$. Assume that $\forall P \in P^{* *}, \exists t<\bar{m},\left[\left\{i \in N, m_{i}=t\right\}=\right.$ $\emptyset$ and $\left.S^{t-1}(P) \neq S^{t}(P)\right] . \quad \forall P \in P^{* *}$, let $\# T(P)=\#\left\{t<\bar{m},\left[\left\{i \in N, m_{i}=t\right\}=\right.\right.$ $\emptyset$ and $\left.\left.S^{t-1}(P) \neq S^{t}(P)\right]\right\}$. By assumption, $\forall P \in P^{* *}, \# T(P) \geq 1$. Moreover, by since $\bar{m}$ is finite, $\forall P \in P^{* *}, \# T(P)$ is finite. By Proposition $1, \forall P \in P^{* *}, \forall t \in \mathbb{N}, S^{t-1}(P) \neq$ $S^{t}(P) \Rightarrow S^{t-1}(P) \subset S^{t}(P)$. Let $P \in P^{* *}$ be such that $\forall P^{\prime} \in P^{* *}, \# T\left(P^{\prime}\right) \geq \# T(P)$ and $\# T\left(P^{\prime}\right)=\# T(P) \Rightarrow \max \left\{t<\bar{m},\left[\left\{i \in N, m_{i}=t\right\}=\emptyset\right.\right.$ and $\left.\left.S^{t-1}(P) \neq S^{t}(P)\right]\right\} \geq$ $\max \left\{t<\bar{m},\left[\left\{i \in N, m_{i}=t\right\}=\emptyset\right.\right.$ and $\left.\left.S^{t-1}\left(P^{\prime}\right) \neq S^{t}\left(P^{\prime}\right)\right]\right\}$. Let $T=\max \{t<\bar{m},[\{i \in$ $\left.N, m_{i}=t\right\}=\emptyset$ and $\left.\left.S^{t-1}(P) \neq S^{t}(P)\right]\right\}$ be the latest period for which $\left[\left\{i \in N, m_{i}=T\right\}=\right.$ $\emptyset$ and $\left.S^{T-1}(P) \neq S^{T}(P)\right]$ is satisfied. By assumption, $T<\bar{m}$.

Let us define $A=S^{T-1}(P) \backslash S^{T}(P) \neq \emptyset$. Let $P^{\prime}=\left(p^{\prime t^{\prime}}\right)_{i^{\prime} \in N, t^{\prime} \in \mathbb{N}} \in \mathcal{P}$ be defined as:

$$
\forall i^{\prime} \in N, \forall t^{\prime} \in \mathbb{N}, p_{i^{\prime}}^{t^{\prime}}= \begin{cases}w_{i^{\prime}} & , \text { if } i^{\prime} \in A \text { and } t^{\prime}=T-1 \\ \min _{i \in S^{T}(P)} w_{i} & , \text { if } i^{\prime} \in S^{T}(P) \text { and } t^{\prime}=T . \\ p_{i^{\prime}}^{t^{\prime}} & , \text { otherwise }\end{cases}
$$

It is straightforward to check that

$$
\begin{gathered}
\Pi(P)-\Pi\left(P^{\prime}\right)= \\
\left(\beta^{T}-\beta^{T-1}\right)\left(\sum_{i \in A} w_{i} \omega_{i}\right) \\
+\beta^{T}\left(w_{S^{T-1}(P)}-w_{S^{T}(P)}\right) \sum_{i \in S^{T-1}(P)} \omega_{i} \\
-\beta^{T} w_{S^{T}(P)} \sum_{i \in A} \omega_{i} .
\end{gathered}
$$

Moreover, $P \in P^{a}$ implies $\Pi(P)-\Pi\left(P^{\prime}\right) \geq 0$. Then,

$$
\begin{array}{r}
\sum_{i \in A} w_{i} \omega_{i} \leq \frac{\beta}{1-\beta}\left[\left(w_{S^{T-1}(P)}-w_{S^{T}(P)}\right)\left(\sum_{i \in S^{T-1}(P)} \omega_{i}\right)\right. \\
\left.-w_{S^{T}(P)}\left(\sum_{i \in A} \omega_{i}\right)\right] .
\end{array}
$$


Now, let us define $S^{+}=\left\{i \in N, m_{i} \leq T+1\right.$ and $\left.w_{i} \geq w_{S^{T-1}(P)}\right\} \backslash S^{T-1}(P)$ and $A^{+}=\left\{i \in N, m_{i} \leq T+1\right.$ and $w_{i} \geq w_{S^{T}(P)}$ and $\left.w_{i}<w_{S^{T-1}(P)}\right\} \backslash A$. Notice that $A^{+}$and $S^{+}$can be empty. Let $P^{\prime \prime}=\left(p^{\prime \prime t^{\prime}}{ }_{i^{\prime}}\right)_{i^{\prime} \in N, t^{\prime} \in \mathbb{N}} \in \mathcal{P}$ be defined as:

$$
\forall i^{\prime} \in N, \forall t^{\prime} \in \mathbb{N}, p^{\prime \prime t^{\prime}}{ }_{i^{\prime}}= \begin{cases}\bar{w}+\delta & , \text { if } i^{\prime} \in A \text { and } t^{\prime}=T \\ w_{S^{T-1}(P)} & , \text { if } i^{\prime} \in S^{+} \cup S^{T-1}(P) \text { and } t^{\prime}=T+1 \\ w_{i}^{\prime} & , \text { if } i^{\prime} \in A^{+} \cup A \text { and } t^{\prime}=T+1 \\ p_{i^{\prime}}^{t^{\prime}} & , \text { otherwise }\end{cases}
$$

It is straightforward to check that

$$
\begin{gathered}
\Pi(P)-\Pi\left(P^{\prime \prime}\right)= \\
\left(\beta^{T}-\beta^{T+1}\right)\left(\sum_{i \in A} w_{i} \omega_{i}\right) \\
+\beta^{T+1}\left(w_{S^{T}(P)}-w_{S^{T-1}(P)}\right)\left(\sum_{i \in S^{T-1}(P)} \omega_{i}+\sum_{i \in S+} \omega_{i}\right) \\
+\beta^{T+1} \sum_{i \in A^{+}} \omega_{i}\left(w_{S^{T}(P)}-w_{i}\right) \\
+\beta^{T+1} w_{S^{T}(P)} \sum_{i \in A} \omega_{i}
\end{gathered}
$$

Moreover, $P \in P^{a}$ implies $\Pi(P)-\Pi\left(P^{\prime \prime}\right) \geq 0$. Then,

$$
\begin{array}{r}
\sum_{i \in A} w_{i} \omega_{i} \geq \frac{\beta}{1-\beta}\left[\left(w_{S^{T-1}(P)}-w_{S^{T}(P)}\right)\right. \\
\left(\sum_{i \in S^{T-1}(P)} \omega_{i}+\sum_{i \in S+} \omega_{i}\right) \\
+\sum_{i \in A^{+}} \omega_{i}\left(w_{i}-w_{S^{T}(P)}\right) \\
\left.-w_{S^{T}(P)} \sum_{i \in A} \omega_{i}\right] .
\end{array}
$$

Using Equations 3 and 4, we have

$$
\begin{aligned}
\sum_{i \in A} w_{i} \omega_{i}=\frac{\beta}{1-\beta} & {\left[\left(w_{S^{T-1}(P)}-w_{S^{T}(P)}\right)\left(\sum_{i \in S^{T-1}(P)} \omega_{i}\right)\right.} \\
& \left.-w_{S^{T}(P)}\left(\sum_{i \in A} \omega_{i}\right)\right] .
\end{aligned}
$$


And then, $\Pi(P)=\Pi\left(P^{\prime}\right)=\Pi\left(P^{\prime \prime}\right)$. Since, by assumption $P \in P^{a}$, we have, $P^{\prime \prime} \in P^{a}$. Moreover, it is straightforward to check that $P^{\prime \prime}$ satisfies $\forall i \in N, \forall t \in \mathbb{N}$,

1. $i \notin S^{t}\left(P^{\prime \prime}\right) \Rightarrow p^{\prime \prime}{ }_{i}=\bar{w}+\delta$,

2. $t=0 \Rightarrow\left[i \in S^{t}\left(P^{\prime \prime}\right) \Rightarrow p_{i}^{\prime \prime}=w_{i}\right]$,

3. $t>0 \Rightarrow\left[i \in S^{t}\left(P^{\prime \prime}\right) \Rightarrow p_{i}^{\prime \prime}=\min \left(w_{i}, \min _{t^{\prime}<t, i^{\prime} \in S^{t^{\prime}}\left(P^{\prime \prime}\right)} w_{i^{\prime}}\right)\right]$.

Hence, $P^{\prime \prime} \in P^{* *} \subseteq P^{*}$. Moreover, $\# T\left(P^{\prime}\right)<\# T(P)$ or $\left[\# T\left(P^{\prime \prime}\right)=\# T(P)\right.$ and $\max \{t<$ $\bar{m},\left[\left\{i \in N, m_{i}=t\right\}=\emptyset\right.$ and $\left.\left.S^{t-1}(P) \neq S^{t}(P)\right]\right\}<\max \left\{t<\bar{m},\left[\left\{i \in N, m_{i}=t\right\}=\right.\right.$ $\emptyset$ and $\left.\left.S^{t-1}\left(P^{\prime \prime}\right) \neq S^{t}\left(P^{\prime \prime}\right)\right]\right\}$ contradicting the definition of $P$.

Proof of Proposition 3: Follows directly from Lemma 11.

Proof of Proposition 4: By Proposition 3, $\exists P \in P^{a}, \forall t>1, S^{t}(P)=S^{t-1}(P)$. Obviously, by Lemma $7, S^{0}(P)=\overline{S(P)} \in \mathcal{S}^{0}$. Let $S^{\prime} \in \mathcal{S}_{0}$. Let $P^{\prime}=\left(p_{i^{\prime}}^{\prime t^{\prime}}\right)_{i^{\prime} \in N, t^{\prime} \in \mathbb{N}} \in \mathcal{P}$ be defined as:

$$
\forall i^{\prime} \in N, \forall t^{\prime} \in \mathbb{N}, p_{i^{\prime}}^{t^{\prime}}= \begin{cases}w_{i^{\prime}} & , \text { if } i^{\prime} \in S^{\prime} \text { and } t^{\prime}=0 \\ w_{S^{\prime}} & , \text { if } i^{\prime} \in S^{\prime} \text { and } t^{\prime}>0 \\ \bar{m}+\delta & , \text { otherwise }\end{cases}
$$

It is straightforward to check that

$$
\Pi\left(P^{\prime}\right)=\sum_{i \in S^{\prime}} w_{i} \omega_{i}+\frac{\beta}{1-\beta} w_{S^{\prime}}\left(\sum_{i \in S^{\prime}} \omega_{i}\right) .
$$

Since, $S^{\prime} \in \mathcal{S}^{0}$ and $S \in \mathcal{S}^{0}, \Pi(P)=\Pi\left(P^{\prime}\right)$. Hence, $P^{\prime} \in P^{a}$. Moreover, obviously, $\overline{S\left(P^{\prime}\right)}=S^{\prime}$

Proof of Proposition 5: Let $P \in P^{a}$ be such that $\overline{S(P)} \notin \mathcal{S}^{0}$. By Lemma $6, \tilde{P} \in P^{a}$ and by Lemma $5, \overline{S(\tilde{P})} \notin \mathcal{S}^{0}$. By Lemma 10, $\exists P^{\prime} \in P^{*}, \forall t>0, S^{t-1}\left(P^{\prime}\right)=S^{t}\left(P^{\prime}\right)=\overline{S(\tilde{P})}$. 
Then, by definition of $P^{*}$,

$$
\Pi\left(P^{\prime}\right)=\sum_{i \in \overline{S(\tilde{P})}} w_{i} \omega_{i}+\frac{\beta}{1-\beta} w_{\overline{S(\tilde{P})}}\left(\sum_{i \in \overline{S(\tilde{P})}} \omega_{i}\right) .
$$

With Proposition 4, $P^{\prime} \in P^{*} \subseteq P^{a}$ and $\overline{S(\tilde{P})} \notin \mathcal{S}^{0}$ is a contradiction.

Proof of Proposition 6: Let $P \in P^{a}$ and let $T \in \mathbb{N}$ be the earliest period for which $S^{T}(P)=\overline{S(P)}$ and $T>\bar{m}$. By Proposition $2, \forall S \in \mathcal{S}^{0}, \overline{S(P)} \subset S$ or $S \subseteq \overline{S(P)}$. Assume $\forall S \in \mathcal{S}^{0}, \overline{S(P)} \subset S$. Let $S \in \mathcal{S}^{0}$.

By Lemmas 6 and 7, $\tilde{P} \in P^{a}, T$ is the earliest period for which $S^{T}(\tilde{P})=\overline{S(\tilde{P})}$ and $T>\bar{m}$. Moreover, $\overline{S(\tilde{P})} \subset S$. Let $S^{+}=S \backslash \overline{S(\tilde{P})} \neq \emptyset$.

Let $P^{\prime}=\left(p^{\prime t^{\prime}}\right)_{i^{\prime} \in N, t^{\prime} \in \mathbb{N}} \in \mathcal{P}$ be defined as:

$$
\forall i^{\prime} \in N, \forall t^{\prime} \in \mathbb{N}, p_{i^{\prime}}^{\prime t^{\prime}}=\left\{\begin{array}{ll}
w_{i} & , \text { if } i^{\prime} \in S^{+} \text {and } t^{\prime}=T+1 \\
w_{S} & , \text { if } i^{\prime} \in S \text { and } t^{\prime}>T+1 \\
\tilde{p}_{i^{\prime}} & , \text { otherwise }
\end{array} .\right.
$$

It is straightforward to check that

$$
\begin{gathered}
\Pi(\tilde{P})-\Pi\left(P^{\prime}\right)= \\
=\beta^{T+1}\left[\left(\sum_{i \in \overline{S(\tilde{P})}} w_{i} \omega_{i}\right)+\frac{\beta}{1-\beta}\left(w_{\overline{S(\tilde{P})}} \sum_{i \in \overline{S(\tilde{P})}} \omega_{i}\right)\right. \\
\left.-\left(\sum_{i \in S} w_{i} \omega_{i}\right)-\frac{\beta}{1-\beta}\left(w_{S} \sum_{i \in S} \omega_{i}\right)\right]
\end{gathered}
$$

By definition of $\mathcal{S}^{0}$ and since by assumption, $\overline{S(\tilde{P})} \notin \mathcal{S}^{0}$,

$$
\begin{gathered}
\left(\sum_{i \in S} w_{i} \omega_{i}\right)+\frac{\beta}{1-\beta}\left(w_{S} \sum_{i \in S} \omega_{i}\right)> \\
\left(\sum_{i \in \overline{S(\tilde{P})}} w_{i} \omega_{i}\right)+\frac{\beta}{1-\beta}\left(w_{\overline{S(\tilde{P})}} \sum_{i \in \overline{S(\tilde{P})}} \omega_{i}\right) .
\end{gathered}
$$


Hence, $\operatorname{Pi}(\tilde{P})<P i\left(P^{\prime}\right)$ contradicting the assumption that $\tilde{P} \in P^{a}$.

\section{DEFINITION 7}

Let the function $\pi$ be defined as follows: $\forall A \subseteq N$,

$$
\pi(A)=\sum_{i \in A} \omega_{i} w_{i}+\frac{\beta}{1-\beta} \sum_{i \in A} \omega_{i} w_{A} .
$$

Proof of Proposition 7: Let $P=\left(p_{i}^{t}\right)_{i \in N, t \in \mathbb{N}} \in P^{a}$ be such that $\overline{S(P)} \notin \mathcal{S}^{0}$. By Lemma 10 , we can consider $\forall t>1, S^{t-1}=S^{t}(P)$. By Lemma 5 and 6 , we can consider $P \in P^{*}$. Let us define $A=S^{0}(P), A^{+}=\left\{i \in N, w_{i} \geq w_{A}\right\}$ and $B=S^{1}(P) \backslash A^{+}$. Then, by definition, $\overline{S(P)}=A^{+} \cup B$. It is straightforward to check that

$$
\Pi(P)=\sum_{i \in A} \omega_{i} w_{i}+\beta \sum_{i \in A^{+}} \omega_{i}\left(w_{A^{+}}-w_{i}\right)+\beta \pi\left(A^{+} \cup B\right) .
$$

Let $S \in \mathcal{S}^{0}$.

I. Assume $A^{+} \subseteq S$.

Let $P^{\prime}=\left(p_{i^{\prime}}^{\prime t^{\prime}}\right)_{i^{\prime} \in N, t^{\prime} \in \mathbb{N}} \in \mathcal{P}$ be defined as:

$$
\forall i^{\prime} \in N, \forall t^{\prime} \in \mathbb{N}, p_{i^{\prime}}^{\prime t^{\prime}}=\left\{\begin{array}{ll}
w_{i} & , \text { if } i^{\prime} \in S \backslash A^{+} \text {and } t^{\prime}=1 \\
w_{S} & , \text { if } i^{\prime} \in S \text { and } t^{\prime}>1 \\
p_{i^{\prime}}^{t^{\prime}} & , \text { otherwise }
\end{array} .\right.
$$

It is straightforward to check that

$$
\Pi\left(P^{\prime}\right)=\sum_{i \in A} \omega_{i} w_{i}+\beta \sum_{i \in A^{+}} \omega_{i}\left(w_{A}-w_{i}\right)+\beta \pi(S) .
$$

Then, $\Pi(P)-\Pi\left(p^{\prime}\right)=\pi\left(A^{+} \cup B\right)-\pi(S)$. However, $S \in \mathcal{S}^{0}$ and $\overline{S(P)}=A^{+} \cup B \notin \mathcal{S}^{0}$ imply $\Pi(P)-\Pi\left(p^{\prime}\right)=\pi\left(A^{+} \cup B\right)-\pi(S)<0$. This contradicts the fact that $P \in P^{a}$.

II. Assume $S \subset A^{+}$.

Let us define $S_{0}=\left\{i \in N, m_{i}=0\right\}, S_{1}=\left\{i \in S, w_{i} \geq w_{S_{0}}\right\}$ and $S_{2}=S \backslash S_{1}$.

Let $P^{\prime \prime}=\left(p^{\prime \prime \prime}{ }^{\prime \prime}\right)_{i^{\prime} \in N, t^{\prime} \in \mathbb{N}} \in \mathcal{P}$ be defined as:

$$
\forall i^{\prime} \in N, \forall t^{\prime} \in \mathbb{N}, p_{i^{\prime \prime}}^{\prime t^{\prime}}= \begin{cases}w_{i} & , \text { if } i^{\prime} \in S_{0} \text { and } t^{\prime}=0 \\ w_{S_{0}} & , \text { if } i^{\prime} \in S_{1} \text { and } t^{\prime}=1 \\ w_{i} & , \text { if } i^{\prime} \in S_{2} \text { and } t^{\prime}=1 \\ w_{S} & \text {,if } i^{\prime} \in S \text { and } t^{\prime}>1 \\ \bar{w}+\delta & , \text { otherwise }\end{cases}
$$


It is straightforward to check that

$$
\Pi\left(P^{\prime \prime}\right)=\sum_{i \in S_{0}} \omega_{i} w_{i}+\beta \sum_{i \in S_{1}} \omega_{i}\left(w_{S_{0}}-w_{i}\right)+\beta \pi(S) .
$$

Further,

$$
\begin{gathered}
\Pi(P)-\Pi\left(P^{\prime \prime}\right)= \\
\sum_{S \backslash S_{0}} w_{i} \omega_{i}-\sum_{A^{+} \backslash A} w_{i} \omega_{i} \\
-\beta\left(\sum_{i \in S_{1}} \omega_{i}\left(w_{S_{0}}-w_{S}\right)+\sum_{i \in S_{2}} \omega_{i}\left(w_{i}-w_{S}\right)\right) \\
+\beta\left(\pi\left(A^{+} \cup B\right)-\pi(S)\right)+(1-\beta)\left(\pi\left(A^{+}\right)-\pi(S)\right) .
\end{gathered}
$$

$S \in \mathcal{S}^{0}$ and $\overline{S(P)}=A^{+} \cup B \notin \mathcal{S}^{0}$ imply $\pi\left(A^{+} \cup B\right)-\pi(S)<0 S \in \mathcal{S}^{0}$ implies $\pi\left(A^{+}\right)-\pi(S) \leq$ 0 . By the definitions $\sum_{i \in S_{1}} \omega_{i}\left(w_{S_{0}}-w_{S}\right)+\sum_{i \in S_{2}} \omega_{i}\left(w_{i}-w_{S}\right) \geq 0$. Finally, by definition, $S \subset A^{+}$implies $S \backslash S^{0}=\left\{i \in S, m_{i}=1\right\} \subseteq A^{+} \backslash A=\left\{i \in A^{+}, m_{i}=1\right\}$. Hence, $\sum_{S \backslash S_{0}} w_{i} \omega_{i}-\sum_{A^{+} \backslash A} w_{i} \omega_{i} \leq 0$. Then, $\Pi(P)-\Pi\left(P^{\prime \prime}\right)<0$ which contradicts the fact that $P \in P^{a}$.

Proof of Proposition 8: The proof is similar to the proof of Proposition 7 with weak inequalities. 